\title{
Influence of $w / c$ ratio on rate of chloride induced corrosion of steel reinforcement and its dependence on ambient temperature
}

\author{
V Ž̀IVICA \\ Institute of Construction and Architecture of the Slovak Academy of Sciences, Dúbravská cesta 9, 84503 Bratislava, \\ Slovak Republic
}

MS received 22 January 2003

\begin{abstract}
The permeability of the embedding cement material for the rate of chloride induced corrosion when the ambient temperature is increased has found a dominant position. The importance of the given permeability in the process is based on the fact that it represents a factor conditioning the possibility of the escaping of the unambiguous reaction partners, oxygen and water vapour, from the system embedding cement material-steel, as the ambient temperature is increased. The resulting effect is a slowing down of the corrosion rate when the $w / c$ ratio over the value 0.6 and the ambient temperature over the value $40^{\circ} \mathrm{C}$ are increased.

Due to the similarity of the chemism of the corrosion process of steel reinforcement, independent of the action of aggressive species, the found relationships are generally valid, e.g. for the corrosion due to carbonation.
\end{abstract}

Keywords. Chloride induced corrosion; steel reinforcement; rate; water-cement ratio; ambient temperature; rate prediction.

\section{Introduction}

A basic precondition of the possibility of development of steel reinforcement is the transport of aggressive species into concrete. Transport phenomena such as diffusion, adsorption and permeability join together to cause penetration of aggressive medium.

Since the mechanism of all deterioration processes are permeability oriented, it is essential that the concrete should be dense and impervious for high corrosion resistance performance of concrete structures.

It is known that pore size distribution and on it dependent permeability of cement matrix in concrete is a direct function of the $w / c$ ratio, when the aggregates are dense and the permeability is governed by the permeability of the cement matrix (Reinhardt 1992; Aitkin 1994).

The important role of $w / c$ ratio in the permeability capacity of concrete is extensively known with the existence of the range between 0.40 and 0.60 where maximum permeability is obtained. Significantly reduced permeability is reported when $w / c$ ratio is below 0.45 , preferably $0 \cdot 40$. It has been shown that concretes with low $w / c$ ratio are less sensitive to carbonation and to external chemical attack.

The significance of $w / c$ ratio for the transport effects is based on the fact that increase in $w / c$ ratio leads to an increase in the size of the pores and porosity. At the same hydration degree, a low $w / c$ ratio produces fewer pores and of smaller size, whereas a high $w / c$ ratio leads to more pores of larger diameter, e.g. a reduction in the $w / c$ ratio from 0.75 to 0.57 leads to a reduction in penetration depth to about one-third (Basher et al 1995).

Undoubtedly the rate of corrosion of steel reinforcement on the ambient temperature is dependent only on chemical reaction. However, it is surprisingly a subject of only a minimal interest. Significance and influence of the ambient temperature as a factor of steel reinforcement corrosion rate is evaluated by means of the universal dependence of the chemical reaction on the ambient temperature. According to this the rate of chemical reaction is accelerated as the ambient temperature is increased. But experimentally it has been found that dependence of the rate of steel reinforcement corrosion on the ambient temperature is more complex. This complexity is shown by an accelerating effect up to a temperature of $40^{\circ} \mathrm{C}$ followed by an inhibiting effect occurring over this temperature. It seems that the main cause of this phenomenon is the decrease of the oxygen solubility in the pore solution when the ambient temperature is increased (Živica et al 1997; Ž Zivica 2002).

The results of the experimental study on the influence of $w / c$ ratio on the rate of chloride-induced corrosion and its dependence on the ambient temperature are reported here. A mathematical expression of the found relationships which represents a possibility for the mathematical prediction of the corrosion rate and service life of corroding reinforced concrete structures is also given here. 


\section{Experimental}

Mortar test specimens-prisms $40 \times 40 \times 160 \mathrm{~mm}$ with the embedded steel specimens also called corrosion sensors, were used for the study. The materials used for the preparation of the test specimens were mortar mixtures with the ratio Portland cement: silica sand $1: 3, w / c$ ratios $0.45,0.60$ and 0.75 and $4 \%$ calcium chloride opposite to the portion of cement in the mixtures.

Ordinary Portland cement (STN 722121 Portland cement) and silica sand (STN 721208 Testing Sands) were used in the study. Steel test specimens/corrosion sensors were used (electrical resistance method) for the study of steel corrosion. For their preparation, steel 11 373 (STN 411373 Steel 11 373) was used.

The prepared mortar test specimens were cured as follows: first 3 days in the moulds at a relative humidity $(\mathrm{RH})$, ca $95 \%$ and temperature, $20^{\circ} \mathrm{C}$, after demoulding they were cured at $\mathrm{RH}$ for ca $60 \%$ and at temperatures 20,40 and $60^{\circ} \mathrm{C}$.

The following properties of the test specimens were observed: compressive strength and bulk weight; pore structure by mercury intrusion method using the microporosimeter mod. 200 and macroporosimeter Unit 120 CARLO ERBA SCIENCE, with the possibility to estimate pores with the radius from $0.35 \mathrm{~nm}$ to ca $0.3 \mathrm{~mm}$, when the contact angle $141.3^{\circ}$ and surface tension of mercury $0.48 \mathrm{Nm}^{-1}$ for the calculation of the results were used; coefficient of water permeability using a new porosimetric method (Bágel and Zivica 1997); and stationary electrode potential and electrical resistance of the corrosion sensors (Živica 1995, 2000).

\section{Results and discussion}

\subsection{Properties of embedding mortars}

Values of the mechanical properties and of pore structure parameters of the mortars are given in table 1 and illustrated in figure 1 . As it could be expected, it may be seen that the increase in the values of $w / c$ ratio used caused a significant decrease in the values of compressive strength of mortars, and their bulk weight. Similarly, the same effect can be seen at the values of the pore structure parameters showing the increase in pore volume, pore median and total porosity. Significant and interesting is the increase of the coefficient of water permeability as $w / c$ ratio was increased. This increase represents $1600 \%$ when $w / c$ ratio of 0.45 and 0.75 mortars are compared. The comparison with the value of coefficient of $0.60 \mathrm{w} / \mathrm{c}$ mortar shows an increase of $225 \%$.

The shown results document that the properties of the used mortar, especially their water permeability - a significant transport parameter-were satisfactory and suitable for given aim of study.

\subsection{Properties of the embedded corrosion sensors}

As it may be seen in figure 2 the values of electrode potential with time of curing show very irregular changes. Therefore, it was possible to evaluate only common trends of development of electrode potential. According to the shown results the corrosion sensors with the values over $-400 \mathrm{mV}$ vs SCE in the corrosive state occurred. No dependence of these changes on the $w / c$ ratio used and the ambient temperature, has been found. One cause

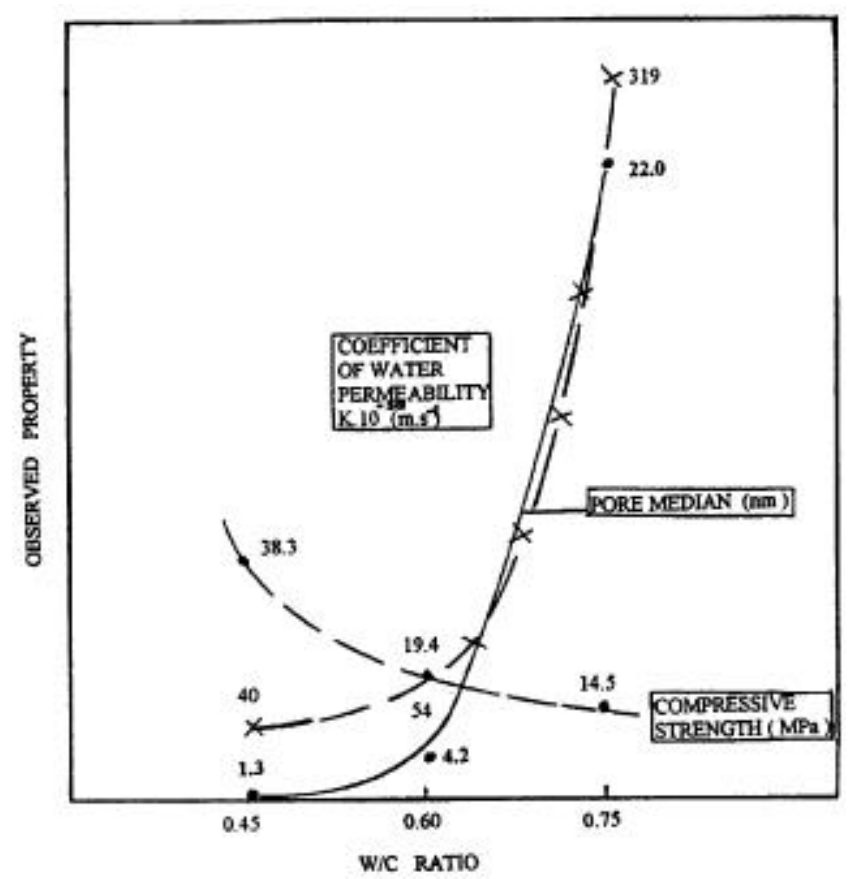

Figure 1. Dependence of the properties of the used mortars on the $w / c$ ratio used.

Table 1. Mechanical properties and pore structure parameters of the used mortars.

\begin{tabular}{lccccccc}
\hline$w / c$ & $\begin{array}{c}\text { Compressive } \\
\text { strength (MPa) }\end{array}$ & $\begin{array}{c}\text { Bulk weight } \\
\left(\mathrm{kg} \cdot \mathrm{m}^{-3}\right)\end{array}$ & $\begin{array}{c}\text { Pore volume } \\
\left(\mathrm{mm}^{3} \cdot \mathrm{g}^{-1}\right)\end{array}$ & $\begin{array}{c}\text { Pore median } \\
(\mathrm{nm})\end{array}$ & $\begin{array}{c}\text { Macropore } \\
\text { content }(\%)\end{array}$ & $\begin{array}{c}\text { Total } \\
\text { porosity }(\%)\end{array}$ & $\begin{array}{c}\text { Coefficient of water } \\
\text { permeability }\left(\mathrm{m} \cdot \mathrm{s}^{-1}\right)\end{array}$ \\
\hline $0 \cdot 45$ & $38 \cdot 3$ & 2290 & 62 & 40 & $14 \cdot 7$ & $12 \cdot 7$ & $1 \cdot 3 \cdot 10^{-10}$ \\
$0 \cdot 60$ & $19 \cdot 4$ & 2143 & 85 & 54 & $10 \cdot 1$ & $17 \cdot 0$ & $4 \cdot 2 \cdot 10^{-10}$ \\
$0 \cdot 76$ & $14 \cdot 5$ & 2197 & 87 & 319 & $14 \cdot 1$ & $18 \cdot 0$ & $22 \cdot 00 \cdot 10^{-10}$ \\
\hline
\end{tabular}




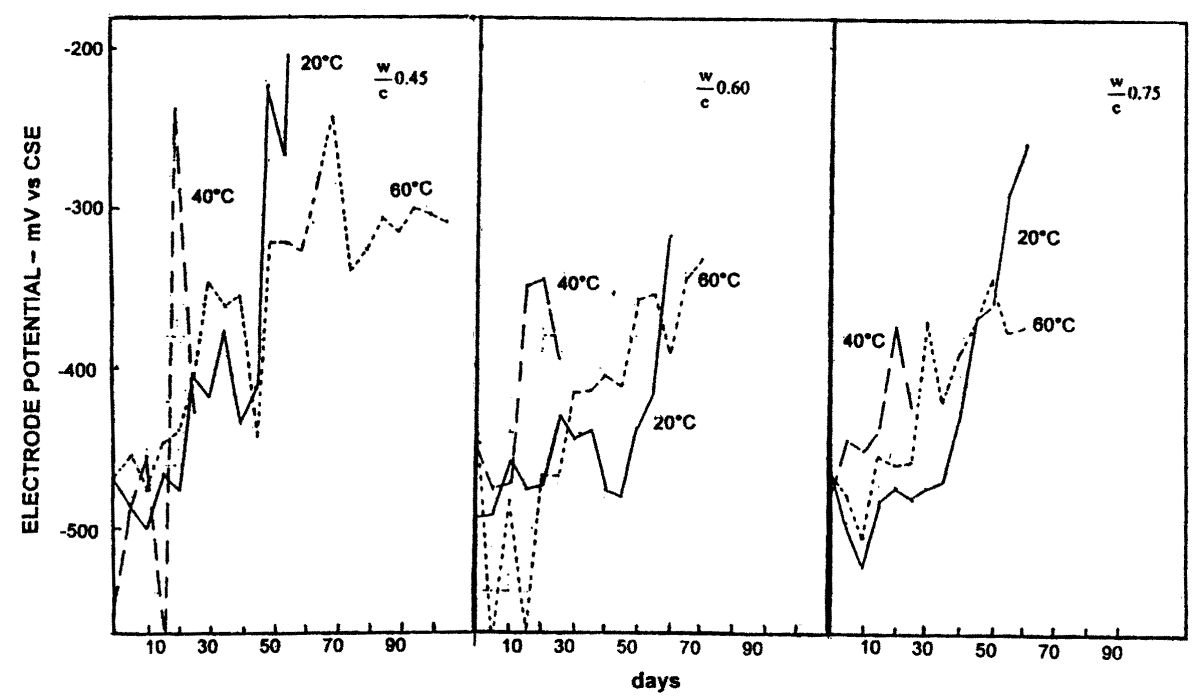

Figure 2. Electrode potential of the embedded corrosion sensors measured opposite to saturated calomel electrode (SCE).

might be the irregularity in the changes of the values of electrode potential superimposing a contingental dependence on the w/c values used.

The results of estimation of changes of electrical resistance give significantly a better picture of the mutual influence of $w / c$ ratio used and ambient temperature, on the corrosion rate as shown in figures $3-5$. They show the increase of electrical resistance of the corrosion sensors indicating their corrosion. At the same time, it may be seen that the rate of corrosion was different and dependent on the $w / c$ ratio used and on the ambient temperature. The increase in the level of both factors caused the increase of corrosion rate, or the corrosion degree expressed as the increase of electrical resistance of corrosion sensors.

A comparison of effect of influence of $w / c$ ratio and ambient temperature on corrosion rate (table 2) is given here: at temperature, $20^{\circ} \mathrm{C}$, a moderate increase of corrosion degree at $w / c$ ratio 0.6 opposite to the one reached at $w / c$ ratio, 0.45 is seen. No difference between the values of the corrosion degree at $w / c$ ratios 0.60 and 0.75 occurred; at temperature, $40^{\circ} \mathrm{C}$, entirely different relationship showing a significant increase in the corrosion degree as the $w / c$ ratios from 0.45 to 0.75 were increased, overcoming an expressed maximum at $w / c$ ratio 0.60 is seen; and at the ambient temperature, $60^{\circ} \mathrm{C}$, the found relationship is again different, on the contrary, it shows at $w / c$ ratio $0 \cdot 60$, the minimal corrosion degree. The values are increased-at $w / c 0.45$ - and decreasedat $w / c 0.76$ - opposite to that reached at temperature, $40^{\circ} \mathrm{C}$.

The given evaluation shows that both $w / c$ ratio used and ambient temperature are very significant and cooperating factors of corrosion rate of chloride induced corrosion of steel reinforcement. This fact is clearly documented also in figure 6.

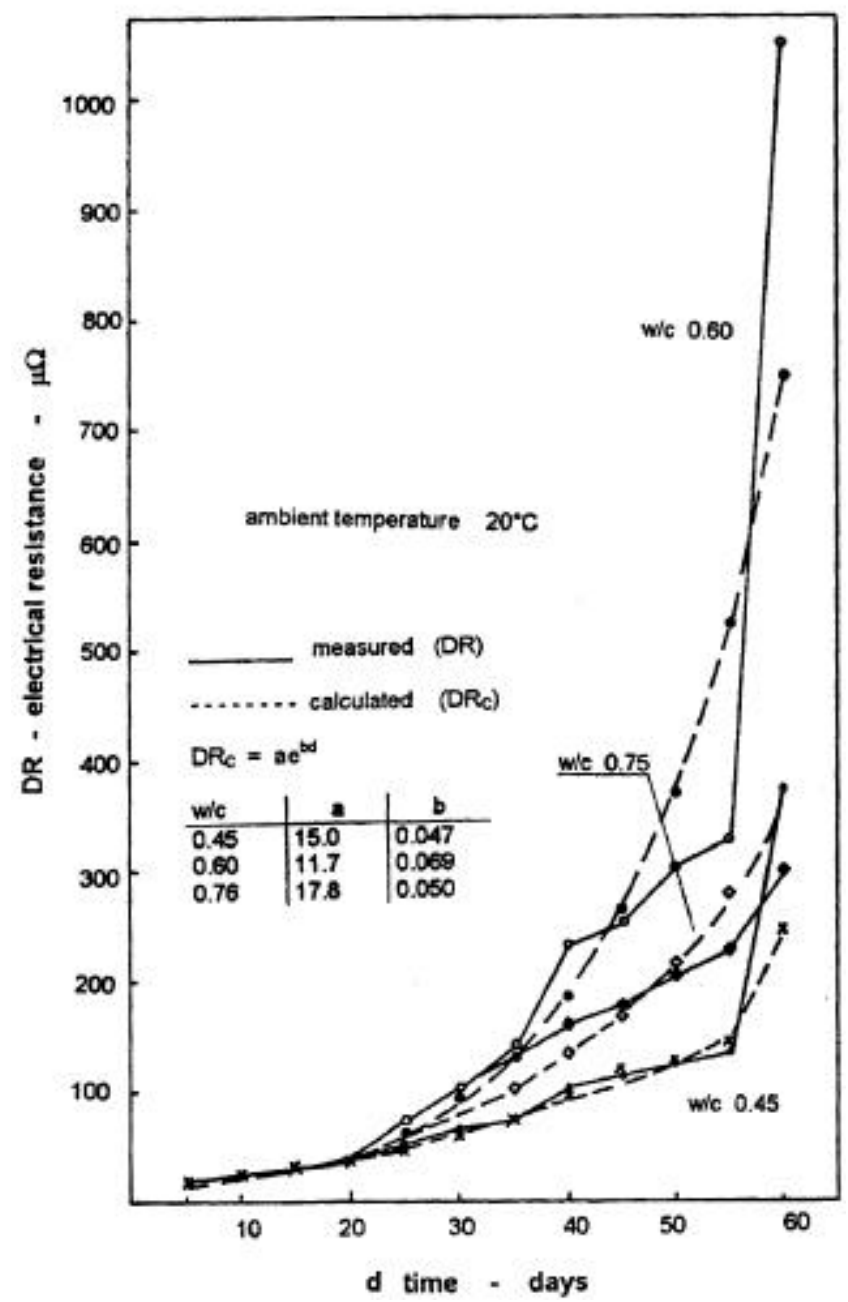

Figure 3. Changes in the electrical resistance of the embedded corrosion sensors at ambient temperature of $20^{\circ} \mathrm{C}$ in dependence of the $w / c$ ratio used. 
Figure 7 shows a drastic increase of corrosion degree at $40^{\circ} \mathrm{C}$ opposite to that at $20^{\circ} \mathrm{C}$ when the permeability of the ambient mortar was increased from 1.3 to 4.2 . $10^{-10} \mathrm{~m} \cdot \mathrm{s}^{-1}$.

The results obtained show evident and significant influence of ambient temperature on the permeability of the embedding material on the corrosion rate. At the same time, the dominant position of the permeability in the process of mutual cooperation of the permeability of the mortar and the ambient temperature can also be seen.

Both these factors in the corrosion process cause: (i) the increase of the ambient temperature which acts as a known acceleration factor of the corrosion process as of a chemical reaction. However, the possibility and the rate of this reaction also on the concentration of oxygen and water in the reaction system, concrete-steel, is significantly dependent. As it is known, the solubility of oxygen in water strongly decreased and water vapour tension, on the contrary, strongly increased with the increase of ambient temperature. This effect for the system, concrete-

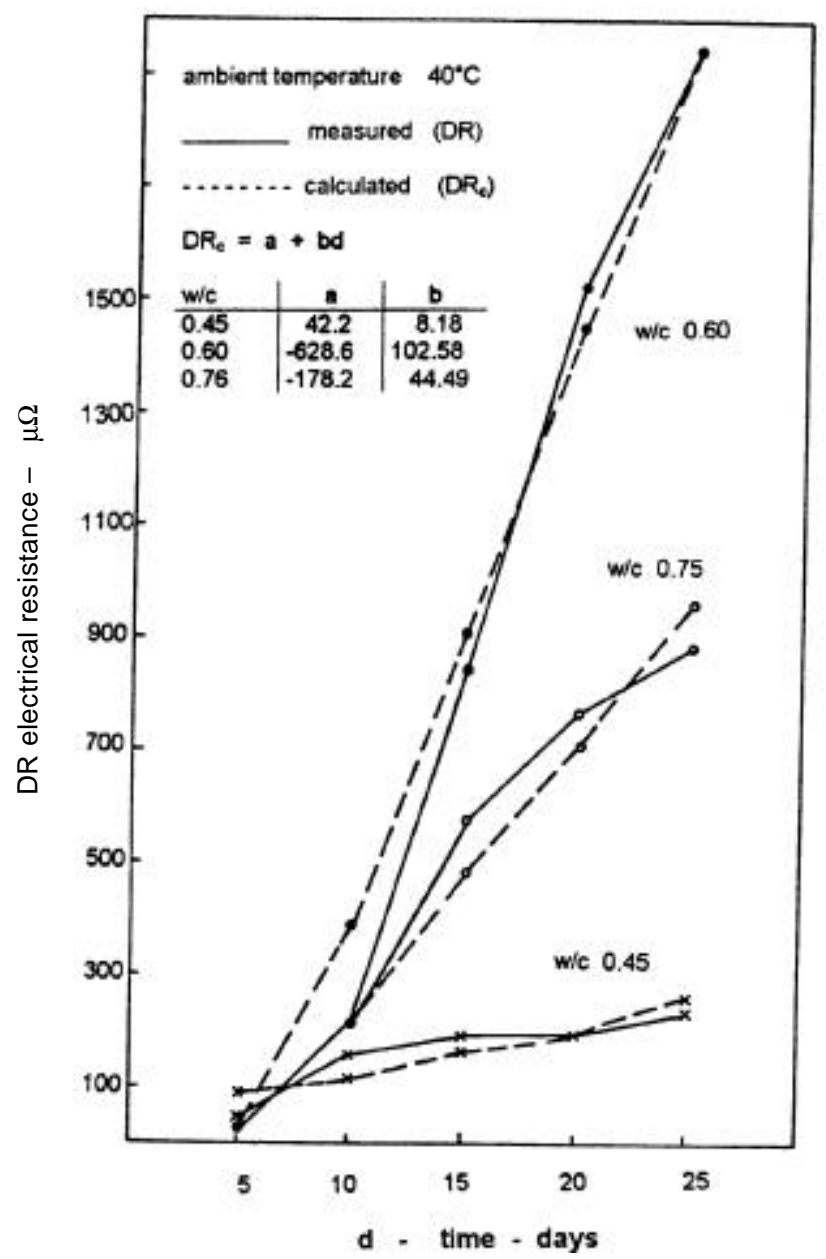

Figure 4. Changes in the electrical resistance of the embedded corrosion sensors at ambient temperature of $40^{\circ} \mathrm{C}$ in dependence of the $w / c$ ratio used. steel, means the decrease of oxygen concentration and the evaporation of water finally resulting in the decrease of the quantity of both unavoidable reaction partners in the corroding system. Naturally, an inhibition of the corrosion process may be a unique subsequent effect. The results unambiguously confirmed this effect on increase of ambient temperature on corrosion rate of steel reinforcement and (ii) the increase in the permeability of the embedding cement based material or for its preparation, $w / c$ ratio used act a factor contributing to the escape of oxygen and water vapour from concrete-steel reinforcement system as the ambient temperature is increased contributing to the decrease of the quantity of the reaction partners-oxygen and water-and to the gradual inhibition of the corrosion rate.

Table 2. Corrosion degree of the corrosion sensors in dependence on $w / c$ ratio and ambient temperature, at 25 days of curing.

\begin{tabular}{lccc}
\hline \multirow{2}{*}{$\begin{array}{l}\text { Ambient } \\
\text { temperature }\end{array}$. } & \multicolumn{2}{l}{$\begin{array}{l}\text { Corrosion degree expressed as increase of electri- } \\
\text { cal resistance of the corrosion sensors }(\mu \Omega)\end{array}$} \\
\cline { 2 - 4 }$w$ & $20^{\circ} \mathrm{C}$ & $40^{\circ} \mathrm{C}$ & $60^{\circ} \mathrm{C}$ \\
\hline 0.45 & 50 & 230 & 750 \\
0.60 & 75 & 1770 & 167 \\
0.76 & 75 & 883 & 660 \\
\hline
\end{tabular}

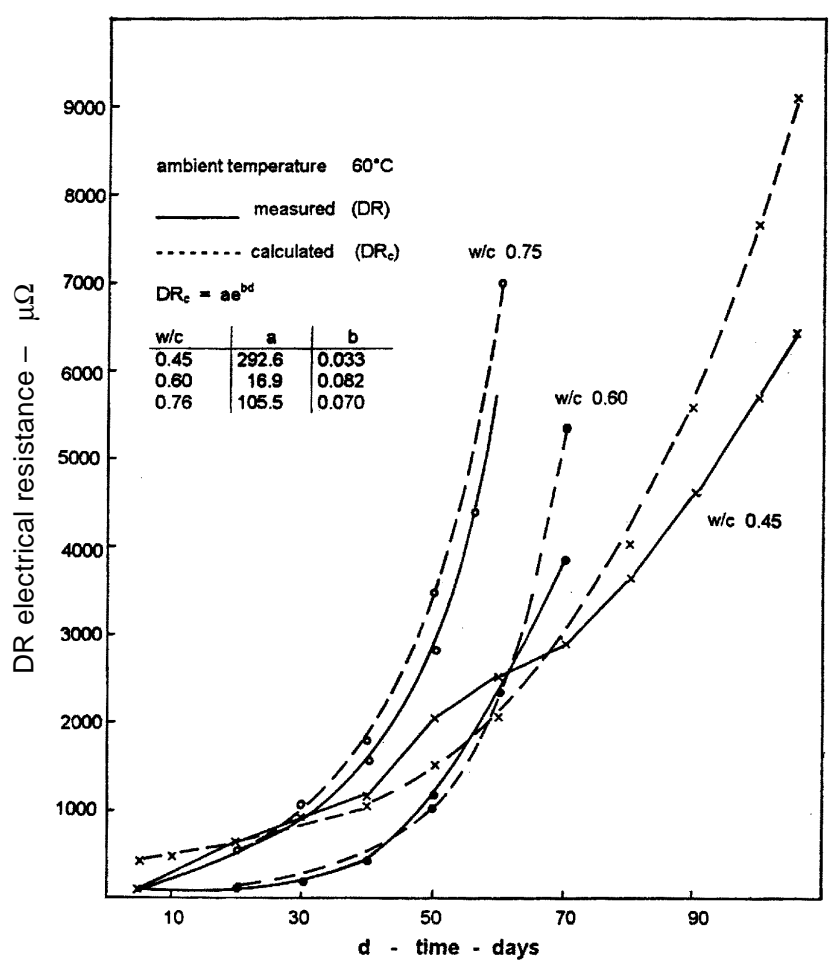

Figure 5. Changes in the electrical resistance of the embedded corrosion sensors at ambient temperature of $60^{\circ} \mathrm{C}$ in dependence of the $w / c$ ratio used. 


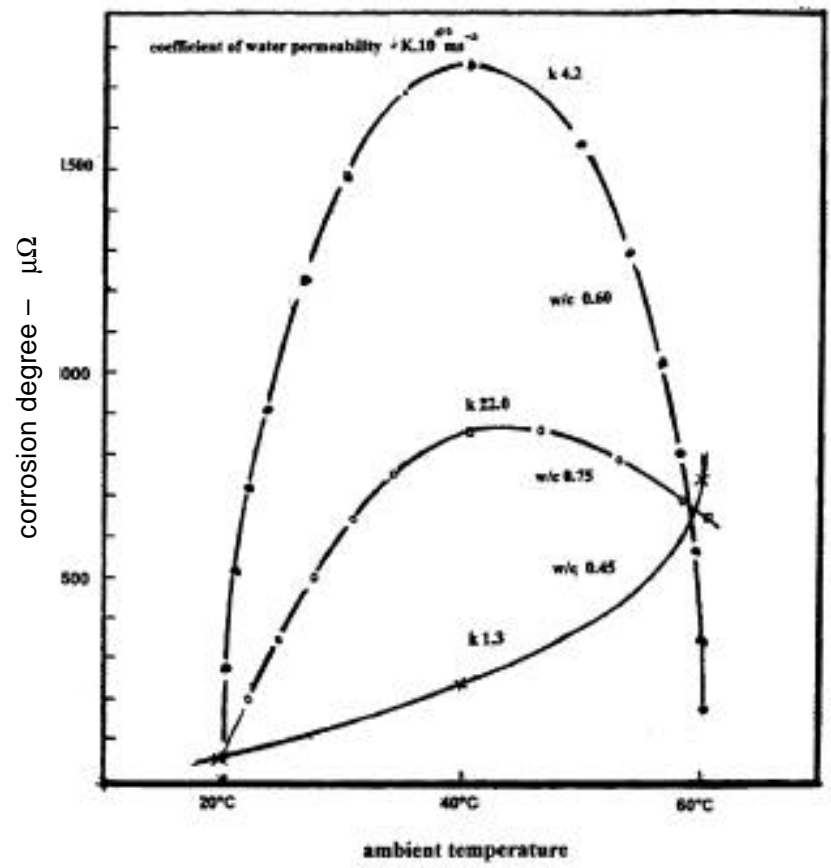

Figure 6. Corrosion degree of the embedded corrosion sensors in dependence of the $w / c$ ratio used and ambient temperature.

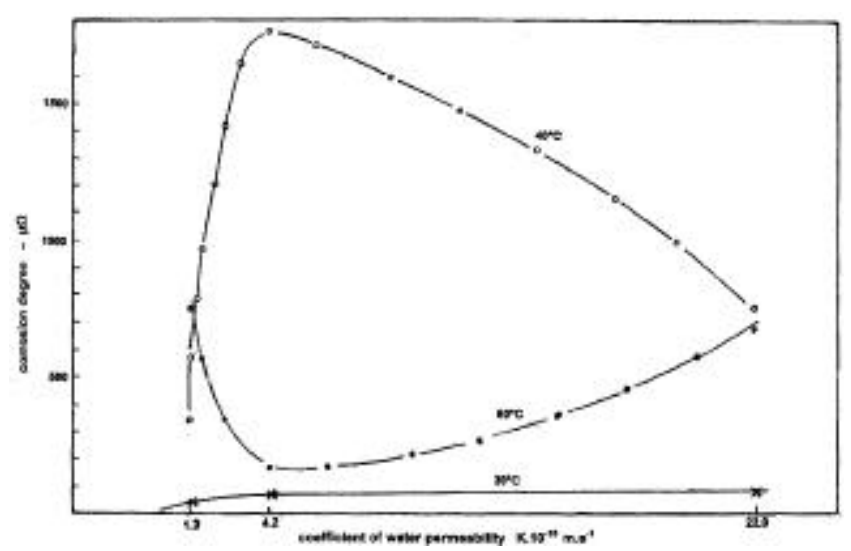

Figure 7. Dependence of the corrosion degree of the corrosion sensors depending on the coefficient of water permeability of the embedding mortar and ambient temperature.

\section{Conclusions}

The results obtained show that $w / c$ ratio used or its dependent permeability of the given cement based material can significantly modify the influence of ambient temperature on the rate of corrosion of the embedded steel reinforcement.

This importance of the permeability of the embedding cement material is based on the fact that it represents a physical barrier conditioning the possibility and rate of transport of the unavoidable reaction partners of oxygen and water vapour from the enveloping environment to the surface of the embedded steel reinforcement.

The found dominant position of the permeability is based on two factors:

(i) The embedding material represents a physical barrier between the environment and embedded steel reinforcement, influencing by its porosity, the transport and quantity of the needed species depending on ambient temperature.

(ii) When the ambient temperature is increased, the solubility of oxygen in pore solution decreased and the evaporation of water vapour intensified. The porous embedding material represents the possibility for the escape of both gaseous components. This effect significantly intensified with the increase of porosity of the embedding material (with the increase of the $w / c$ ratio used) and increase in the ambient temperature.

It has been shown that the known decrease in the quality of the embedding concrete caused by the increase in the $w / c$ ratio used paradoxically may contribute to the protection of the steel reinforcement against corrosion when the ambient temperature is increased over a certain limit.

Considering the fact that presence of oxygen and water vapour are basic for the corrosion process in general, the found relationships between permeability of the embedding cement material and the ambient temperature are generally valid for all types of steel reinforcement corrosion, for example, for corrosion due to carbonation.

\section{Acknowledgements}

The author is thankful to the Slovak grant agency, VEGA, for supporting this work (grant no. 2/1085/21).

\section{References}

Aitkin P C 1994 Concrete technology, past, present and future, in Proc. of V Mohan Malhotra symposium (Detroit: American Concrete Institute) p. 85

Bágel' L' and Živica V 1997 Cement \& Concr. Res. 271225

Basher P M, Long A E and Montgomery F R 1995 Concrete technology, past, present and future, in Proc. of V Mohan Malhotra symposium (Detroit: American Concrete Institute) p. 213

Reinhardt H W 1992 Material science of concrete (ed.) J Skalny (Westerville: Am. Ceram. Soc.) p. 209

Živica V 1995 Mater. \& Struct. 18115

Zivica V 2000 Construct. \& Build. Mater. 14351

Zivica V 2002 Bull. Mater. Sci. 25375

Živica V, Krajci L, Vargová M and Bágel' L' 1997 Construct. \& Build. Mater. 1199 